\title{
A Microbial Electrolysis Cell for Bio-Hydrogen Production and Wastewater Bioremediation
}

\author{
Shmuel Rozenfeld, Rivka Cahan, Hannan Teler, Alex Schechter \\ Department of Chemical Engineering, Ariel University, Ariel 40700, Israel \\ rivkac@ariel.ac.il
}

\section{Extended Abstract}

Bio-hydrogen is expected to play an important role as a non-fossil fuel. Two bioprocesses for bio-hydrogen production from organic materials have been studied extensively: dark fermentation and photofermentation. The major drawbacks of these two bioprocesses are the low yield and the requirement of light, respectively.

Microbial Electrolysis Cells (MEC) are facilities that mostly comprised of dual chambers, anode and cathode. In the anode chamber, there is an attachment of exoelectrogenic bacteria, that biodegrade several carbon sources to $\mathrm{H}_{2} \mathrm{O}$ and $\mathrm{CO}_{2}$, as a result, there is a generation of electrons and protons. The electrons travel to the cathode through an external circuit and the protons through a proton-selective membrane. In the cathode chamber under anaerobic conditions there is a reduction of $\mathrm{H}^{+}$ions to hydrogen. This reduction process occurs under low external voltage of 0.2-0.6 V.

The Objectives of the present research are increasing economic feasibility of MEC for hydrogen production by synthetizing $\mathrm{MoS}_{2}$ catalyst, which is cheaper than the common catalyst, platinum, improving the anode activity by increasing the sustainability of the bacterial anode.

The MEC in this research was consisted of a dual-glass chamber separated by a proton selective membrane. The anode chamber contained Geobacter media and select bacterial strains. The cathode chamber contained phosphate buffer, and equipped with one port for the carbon counter electrode with selected catalysts. The electrodes were brush-coated with the synthetized $\mathrm{MoS}_{2}$ catalyst or platinum. The cathode chamber includes an opening for a gas collection bag. The MEC was placed in a thermostatic bath at $30^{\circ} \mathrm{C}$ and voltage was applied to the circuit at constant potential of: $0.3,0.6$ and $0.9 \mathrm{~V}$ (versus an $\mathrm{Ag} / \mathrm{AgCl}$ reference electrode) using a computer driven potetiostat.

The particle size of the synthetized $\mathrm{MoS}_{2}$ catalyst were found to be $150-250 \mathrm{~nm}$. The electroactivity of the catalysts were examined in an abiotic environment. $\mathrm{In}_{2} \mathrm{SO}_{4}$ solution, the currents produced by Pt were 3.5 fold than synthetized $\mathrm{MoS}_{2}$ catalyst. However, in PB electrolyte the Pt electrochemical performance was only 2 fold. These results indicate that synthetized $\mathrm{MoS}_{2}$ catalyst could be further studied as a low cost alternative to Pt in MEC facility, which based on organic solution. Hydrogen evolution rates were measured in a biotic fully constructed MEC using bacterial anode under selected applied constant potential of 0.3 and $0.6, \mathrm{~V}$. The maximum current density of $6 \mathrm{~A} \mathrm{~m}^{-2}$ obtained in MEC based on the synthetized $\mathrm{MoS}_{2}$ catalyst under $0.6 \mathrm{~V}, 60 \%$ higher from the MEC that was based on Pt catalyst. The hydrogen purity was approximately $100 \%$. The calculated $\mathrm{H}_{2}$ production rate was $0.102 \mathrm{~m}^{3} \mathrm{~d}^{-1} \mathrm{~m}^{-3}$, while the empiric $\mathrm{H}_{2}$ production rate was $0.033 \mathrm{~m}^{3} \mathrm{~d}^{-1} \mathrm{~m}^{-3}$. In conclusion, this study demonstrates the possibility of hydrogen production using bacterial anode and cathode coated with novel synthesized $\mathrm{MoS}_{2}$. Further investigation will be done with domestic wastewater as a source of carbon for the bacterial anode. The expectation is that the MEC will be constructed close to wastewater treatment facilities and that the produced hydrogen will be used for operating wastewater treatment facility. 